\title{
Brief discussion on the water-sediment regulation in the Ningxia- Inner Mongolia reach of the Yellow River under the changing environment
}

\author{
Xiaonan $\mathrm{Li}^{1}$, Chen Zhang ${ }^{2}$, Hongwu Zhang ${ }^{3}$, Lisheng Zhang ${ }^{1}$, Deyu Zhong ${ }^{3}$ \\ ${ }^{1}$ Changjiang Survey, Planning, Design and Research Co., Ltd, Wuhan 430010, China; \\ ${ }^{2}$ Wuhan Urban Construction Investment \&Development Group Co., Ltd, Wuhan 430070, China; \\ ${ }^{3}$ State Key Laboratory of Hydroscience and Engineering, Tsinghua University, Beijing 100084, China)
}

\begin{abstract}
The effective reservoir sediment regulation measure is extremely significant for the sedimentladen river. It should not only extend the reservoir life, but also pose favorable conditions for the management of the river-reservoir system. Especially, the remarkable changes in the hydrological processes challenge to the system in some respects, like flood control, rive training, ecological environment improvement and so on. This paper gives a brief discussion on the representative existing problems in Ningxia-Inner Mongolia reach of the Yellow River. The water-sediment parameters and artificial regulation factors are then summed through a comprehensive literature review. Then we investigate the response to the different scales of floods in the Inner Mongolia reach through a three-dimensional model, in which the simulation region is from Bayangaole gauging station to Toudaoguai gauging station. With respect to the riverbed deformation, it is effective to control the relationship between the incoming water and sediment to restrain the shrinkage of the main channel; and surely that there exists a nonlinear relationship between channel scouring and incoming water-sediment conditions. Through data analysis and simulation results, the response characteristics of different watersediment regulation boundary conditions can be obtained, such as the ratio between sediment concentration and discharge, the discharge duration and the discharge, which is favorable to further water-sediment regulation of the reservoir and the management in Ningxia-Inner Mongolia reach of the Yellow River.
\end{abstract}

\section{INTRODUCTION}

The Ningxia-Inner Mongolia reaches of the Yellow River

(NMYR) flows through the Ningxia Hui Autonomous Region and Inner Mongolia Autonomous Region in China, mainly from Qingtongxia Reservoir to Hekou Town with an estimated mainstream length of $1200 \mathrm{~km}$. Among them, the length of Ningxia River section is about $380 \mathrm{~km}$ with branches of Qingshui River and Kushui River along the way. The Inner Mongolia section is approximately $820 \mathrm{~km}$, during which there are famous ten tributaries and windblown sand into the Yellow River.

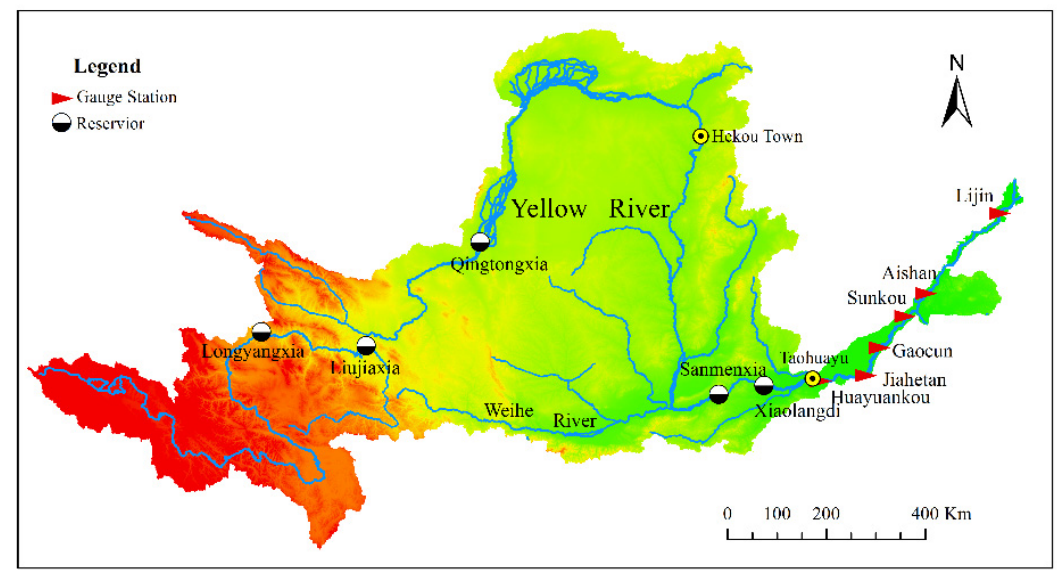

Fig. 1 Sketch map of the Yellow River basin.

Since 1960, a group of key hydraulic complex projects in the upper reaches of the Yellow River have been constructed successively. Meanwhile, due to multiple factors such as interception of erosion and torrent control 
works, upstream reservoir regulation, water use along the river and climate change (Liu et al, 2008), the water and sediment situation in the mainstream of the Yellow River has undergone significant changes (Liu et al., 2012; Shi et al., 2014), which directly affect the riverbed evolution of the river (Ran et al., 2010; Fan et al., 2012).

For the NMYR, since the Liujiaxia and Longyangxia reservoirs were put into operation, the amount of water in the flood season decreased significantly and the distribution of discharge became more uniform during the year, which showed that the number of floods and the peak flow decreased.(Liu et al., 2009; Qin et al., 2011). At the same time, the local socio-economic development has led to a growing amount of water use. The change of water and sediment conditions caused the adjustment of river channel evolution. Especially since 1986, the water and sediment relationship of the NMYR in the flood season has deteriorated. The river siltation is serious and the bankfull discharge has gradually decreased, which has led

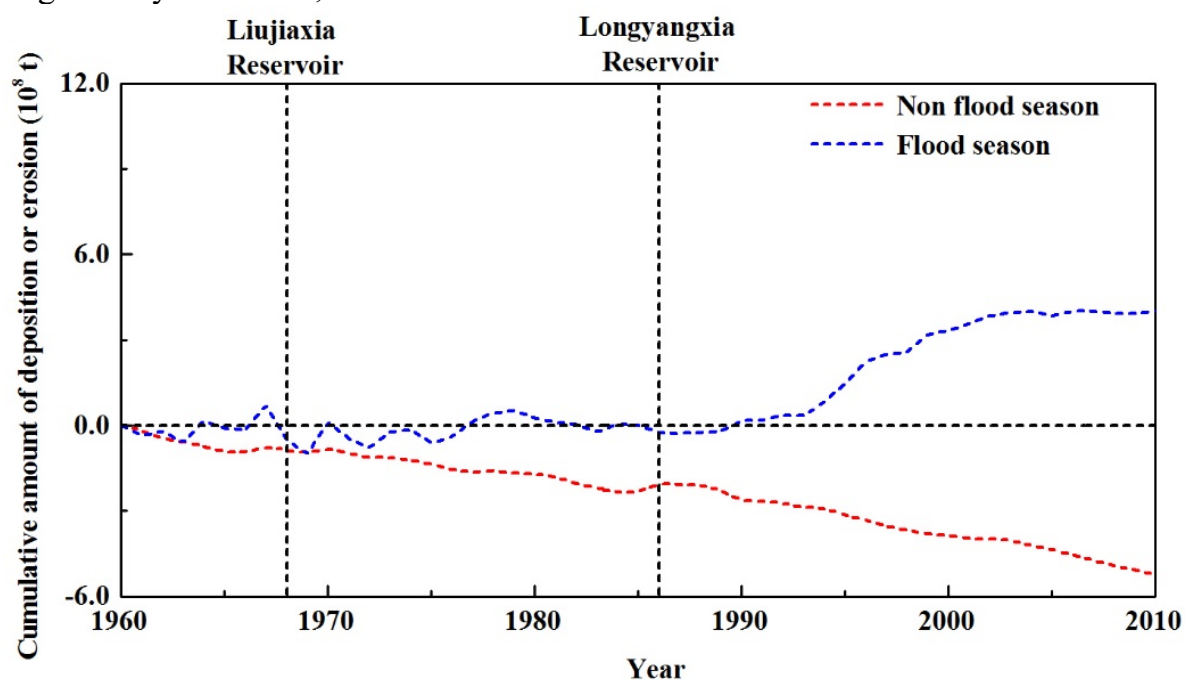

(a)

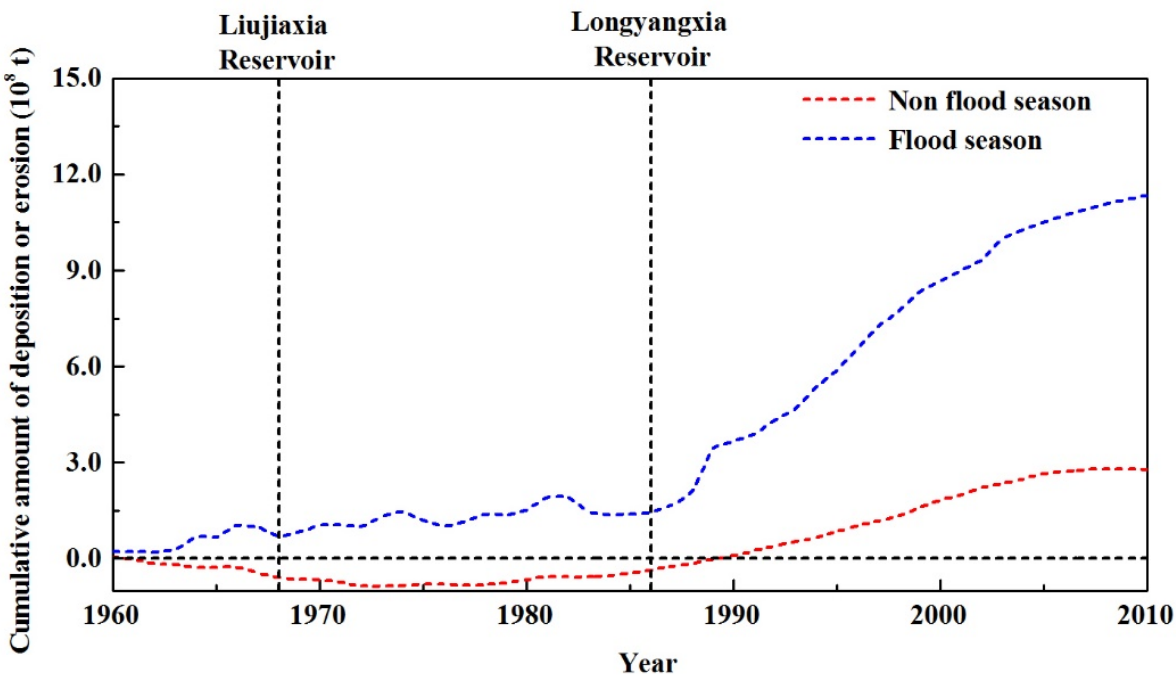

Fig. 2 Cumulative amount of erosion and deposition in NMYR: (a) Ningxia reach; (b) Inner Mongolia reach As a typical alluvial river, the riverbed evolution of the NMYR is closely related to the water-sediment conditions. In order to restore the function of the flood conveyance and sediment transport, much effort has been devoted into the analysis of the relationship between the evolution laws (b)

to the frequent emergence of flood control and ice prevention in this reach (Qin et al., 2011; Fan et al., 2013). Taking the Inner Mongolia reach as an example, the scouring and silting characteristics have transformed from the past micro-deposition to continuous siltation since 1986 , with an average annual sedimentation of $0.6 \times 10^{8}$ tons. Moreover, nearly $80 \%$ of the siltation occurs in the main channel (Wang et al, 2016).

Fig. 2 shows the cumulative scouring and silting process between 1960 and 2010 in the NMYR based on the principle of sediment conservation. It can be demonstrated that the reaches basically maintain the balance of scouring and silting during non-flooded season. In the flood season, since the flood peak is reduced by the storage of the upstream reservoirs and the sediment is merging from ten major tributaries, the long-lasting trend of channel shrinkage keeps unchanged, especially in the Inner Mongolia section.

ongyangxia

and the water-sediment conditions in the flood season ( $\mathrm{Sh}$ et al., 2007; Wang and Fan, 2010; Qin et al., 2011; Wang et al., 2012; Ling et al., 2015; Ma et al., 2016; Zhong et al., 2016), in order to propose the critical conditions for the regulation of water and sediment in this reach. In general, 
the incoming sediment coefficient (ISC), defined as the ratio between sediment concentration and discharge $(\mathrm{S} / \mathrm{Q}$, $\left.\mathrm{kg} . \mathrm{s} / \mathrm{m}^{6}\right)$, is regarded as an index to reflect the proportional relationship between water and sediment. Ling et al. (2015) analyzed the scouring and sedimentation regularity of the section from the Qingtongxia Reservoir to Shizuishan gauging station in the Ningxia reach, and concluded that the critical ISC of the river section is $0.00235 \mathrm{~kg} . \mathrm{s} / \mathrm{m}^{6}$. Hou et al. (2015) analyzed the measured data and proposed the critical ISC in the Inner Mongolia reach is $0.005 \mathrm{~kg} . \mathrm{s} / \mathrm{m}^{6}$. Additionally, a long duration flood with large flood peak occurred in the flood season of 2012 in the NMYR (Zhang et al., 2014), which was the largest flood in the past 30 years. During this flood, the effect of floodplain siltation and channel souring was remarkable, which directly proved that the appropriate water-sediment conditions can effectively control the channel shrinkage in the flood season.

Under the changing conditions of water-sediment, the restoration of water and sediment conveyance capacity in the NMYR is one of the key issues at present $(\mathrm{Hu}, 2016$; Zhang et al., 2016). Therefore, it is of great significance to study the influence of water-sediment regulation on the riverbed evolution, which can not only provide technical support for river training management in the area, but also benefit the utilization of water resources in the upper reaches of the Yellow River.

In this study, the regulation measures are summarized, especially the measure through the reservoir operation. Then a three-dimensional (3-D) numerical models are adopted to assess the responses of the NMYR to the measures, focusing mainly on the river morphology during the man-made flood events.

\section{WATER AND SEDIMENT REGULATION SYSTEM}

There are 16 cascade hydropower stations under planning in the upper reaches of the Yellow River. The existing Longyangxia and Lijiaxia Reservoir (Long-Liu Reservoir) are the two core reservoirs with total flood control capacity of Longyangxia and Liujiaxia Reservoir is 5.5 billion $\mathrm{m}^{3}$. The two reservoirs are always jointly operated to undertake the flood control tasks of the city of Lanzhou and the MNRY.

The Longyangxia Reservoir is located at the entrance of the Yellow River Longyangxia Valley at the junction of Gonghe and Guinan County in Qinghai Province. It is the first cascade hydropower station in the planned upper reaches of the Yellow River. The dam site controls the drainage area of $131000 \mathrm{~km}^{2}$, accounting for the entire basin area of the Yellow River 17.5\%. The main development task of the reservoir is power generation with comprehensive benefits such as flood control, irrigation, ice prevention, breeding and tourism. The normal water level of the reservoir is $2600 \mathrm{~m}$, and the corresponding storage capacity is 24.7 billion $\mathrm{m}^{3}$. The flood control capacity is 4.5 billion $\mathrm{m}^{3}$, and the beneficial reservoir capacity is 19.36 billion $\mathrm{m}^{3}$.

The Liujiaxia Reservoir is located on the main stream of the Yellow River in Yongjing County, Gansu Province.
It has a controlled drainage area of $182000 \mathrm{~km}^{2}$, accounting for one quarter of the total area of the Yellow River. Its main development task is power generation as well as to take into account flood control. The normal water level is $1735 \mathrm{~m}$, and the corresponding storage capacity is 5.7 billion $\mathrm{m}^{3}$. The flood control capacity is 1.0 billion $\mathrm{m}^{3}$, and the beneficial reservoir capacity is 4.2 billion $\mathrm{m}^{3}$.

According to the relevant research (An et al., 2016; Ha et al., 2017), adjusting the operation mode of Long-Liu Reservoir can reduce the rate of siltation growth in NMYR to a certain extent. For instance, the average sedimentation volume can be reduced from the $0.7 \times 10^{8}$ tons to $0.4 \times 10^{8}$ tons through reducing the water retention capacity 4 billion $\mathrm{m}^{3}$, which can also enlarge the overcurrent capacity $400 \mathrm{~m}^{3} / \mathrm{s}$. However, due to the adjustment of the operation mode of Long-Liu Reservoir, the water supply and power generation in the basin will be seriously affected. The annual water supply decreased by about 1 billion $\mathrm{m}^{3}$, and the power generation was reduced by about 1.9 billion kw.h. It can be seen that the existing backbone reservoirs have certain limitations in coordinating the relationship between channel restoration and water supply as well as power generation. The priority scheduling of water supply and power generation has deteriorated the relationship between water and sediment conditions, and caused the river to shrink.

In the context of this situation, it should be taken into consideration to build the Daliushu Reservoir located around the Heishanxia Valley. The Heihexia Valley is located in the upper reaches of the Yellow River, bordering Gansu Province and Ningxia Hui Autonomous Region, starting from the temple in Jingyuan County, Gansu Province, and entering the Hetao Plain in Zhongwei County, Ningxia.

The planned Daliushu dam site controls the area of the Yellow River Basin of $2520 \mathrm{~km}^{2}$, accounting for the total drainage area $33.6 \%$. The average annual runoff is 33.6 billion $\mathrm{m}^{3}$, accounting for the total runoff of the Yellow River $58 \%$, and the average annual sediment transport is only 160 million tons. So the development conditions of water resources are superior (Zhao et al., 2002). The planned normal water level $1380 \mathrm{~m}$ and total storage capacity of 11 billion $\mathrm{m}^{3}$, which can supply enough operation ability to ameliorate the situation of channel shrinkage in the NMYR.

\section{REGULATION INDEX}

On the basis of fully understanding the relationship between the water-sediment conditions and the river channel evolution, more and more scholars believe that it can reduce river siltation through the construction water and sediment regulation index (Zhao et al., 2002; Shen et al., 2007; Liu et al., 2009; Zhang et al., 2009; Duan et al., 2013 Wang et al., 2015; Zhong et al., 2016).

It is widely acceptable that the improvement of flood discharge and the extension of flood duration in flood season can restore sediment transportation pathway. Among them, Shen et al. (2007) analyzed the influence of the Long-Liu Reservoirs on the NMYR and concluded 
that increasing the amount of water in the flood season has a positive effect of siltation reduction, and also propose the required water volume under different conditions. Liu et al. (2009) proposed that the flood discharge should be as high as $1500 \sim 2000 \mathrm{~m}^{3} / \mathrm{s}$ or more, and ensure sufficient water supply during the flood season. Duan et al. (2013) believed that the large-flood between 2500 and $3000 \mathrm{~m}^{3} / \mathrm{s}$ should be focused on; in addition, the duration in one flood should be greater than 14 days and the average annual flood duration should be not less than 30 days. Lin et al. (2015) analyzed the relationship between water-sediment conditions and river evolution in the historical periods, and proposed that the flow should be greater than 2000 $\mathrm{m}^{3} / \mathrm{s}$ or incoming sediment concentration is less than 7 $\mathrm{kg} / \mathrm{m}^{3}$, which can effectively scour river channel in the Inner Mongolia reach of Yellow River. Zhong et al. (2016) suggested that the recent regulation flow should be controlled at the level of $1800 \sim 2000 \mathrm{~m}^{3} / \mathrm{s}$ according to the analysis of water-sediment factors, and the ISC should be controlled within $0.003 \mathrm{~kg} . \mathrm{s} / \mathrm{m}^{6}$.

Of course, some scholars believe that artificial flood peaks are difficult to achieve the restoration of flood and sediment transport functions (Qin Yi, 2009; Wang and Fan, 2010). Wang and Fan (2010) analyzed the discharge-stage relations of different river sections in Inner Mongolia during the flood process, and concluded that although the flooding can create the erosion of the upper reaches of the Sanhuhekou gauging station, the sediment washed downstream will be deposited in the curved section of
Inner Mongolia. Therefore, the selection of man-made flood peaks in this section needs to be treated with caution.

To verify the response of the NMYR, we used the semi-implicit finite-element model (SCHISM) developed by Zhang and Baptista (2008a) to study flood events and the advection-diffusion equation with settling velocity term is valid to represent the suspended load transport to study the water-sand transport characteristics. More details about the model can be referred Li et al. (2018). It is worth mentioning that the regulation measures are put forward on the basis of the exploitation of Daliushu Reservoir.

\section{APPLICATION AND RESULT}

The simulation river reach is the key reach of the NMYR, i.e., the reach from the Bayangol gauging station to the Toudaoguai gauging station with a length of $540 \mathrm{~km}$. The geometric boundary of the computation domain coincided with the Grand Levee of the Yellow River. The domain was divided into556254 unstructured triangular elements in the horizontal and 12 layers in the vertical. Considering that the cross section of the river is typical compound section and the flow pattern behaves great different for the main channel and the floodplain, we refined the grid sizes to $30 \sim 60 \mathrm{~m}$ in the main channels and $100 \sim 300 \mathrm{~m}$ in the floodplains.

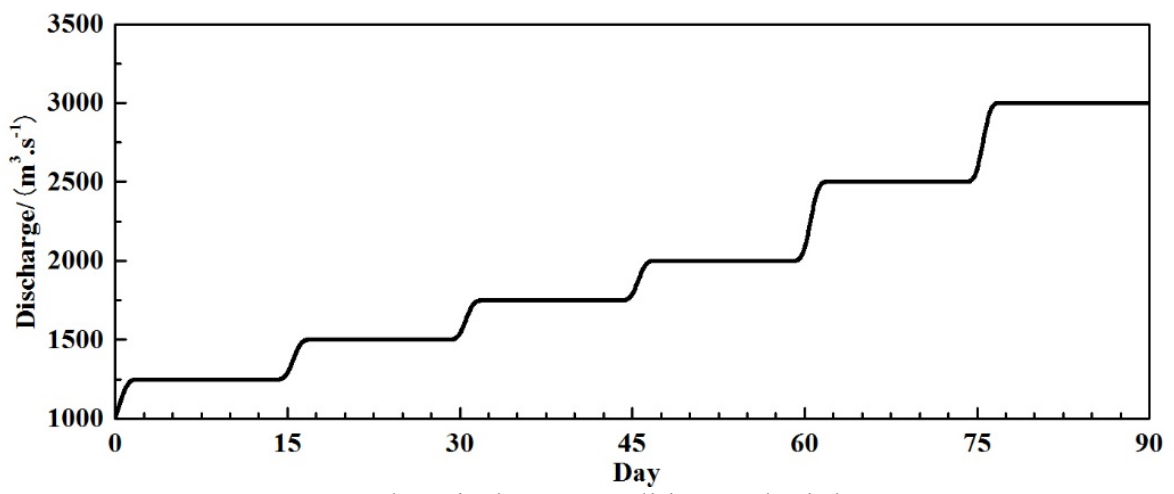

Fig. 3 The Discharge condition at the inlet

The inflow process contains multiple discharge scales: the river section is initialized with discharge $1000 \mathrm{~m}^{3} / \mathrm{s}$, and then six-stage flow processes of the 1250, 1500, 1750, 2000,2500 , and $3000 \mathrm{~m}^{3} / \mathrm{s}$ are increased in turn, during which the process lasts 15 days (Fig. 3 ). According to the research by Zhong et al. (2016), two scenarios about the incoming sediment are designed. In the scenario one, the ISC is $0.0015 \mathrm{~kg} . \mathrm{s} / \mathrm{m}^{6}$ and the value is $0.0025 \mathrm{~kg} . \mathrm{s} / \mathrm{m}^{6}$ for

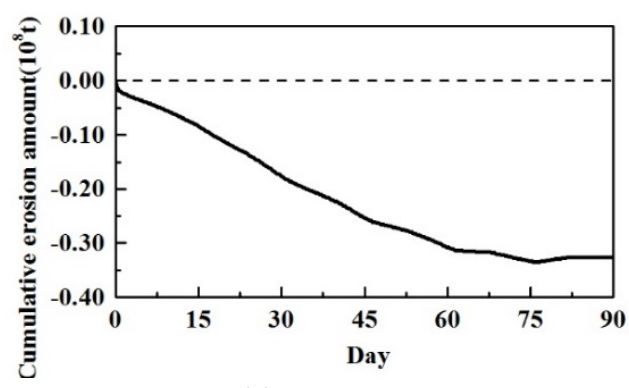

(a) the scenario two. The median diameter of the suspended load is $0.02 \mathrm{~mm}, 0.05 \mathrm{~mm}$, and $0.1 \mathrm{~mm}$, respectively. The daily grading process is based on daily average gradation curve of Bayangol gauging station in 2012 flood. The outlet boundary conditions determined by the measured rating curves at Toudaoguai gauging station. In addition, the calculation does not take into account the branch inflows along the way.

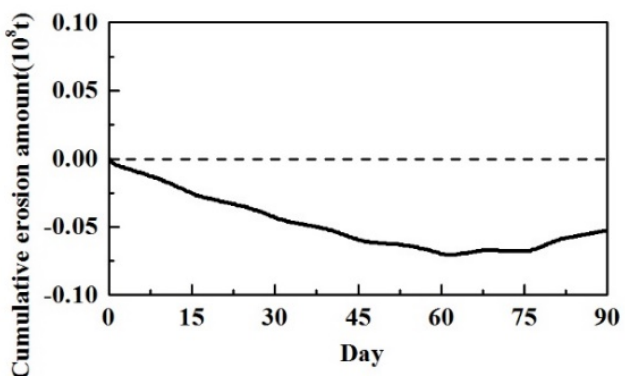

(b)

Fig. 4 Cumulative erosion amount in two simulation scenarios: (a) Scenario one; (b) Scenario two 
Fig. 4 shows the cumulative scouring and silting process for the entire river reach in the two scenarios. It can be found that erosion of the whole river is dominated for two scenarios. The cumulative scouring volume of the whole river is $0.33 \times 10^{8} \mathrm{t}$ in the scenario one, with $1.81 \times 10^{8}$ $\mathrm{t}$ eroded in the main channel but $1.48 \times 10^{8} \mathrm{t}$ deposited in the floodplains. As to the scenario, a net erosion of $0.04 \times 10^{8} \mathrm{t}$ occurs, of which erosion of $1.48 \times 10^{8}$ and deposition of $1.44 \times 10^{8} \mathrm{t}$ are distributed in the main channel and floodplains, respectively.

In addition, according to the response law of the main channel under different water-sediment conditions, we analyzed its erosion under different inflow conditions (Table 1) by defining the erosion intensity of main channel:

$$
\phi=\frac{\Delta M}{\Delta t}
$$

where $\phi$ is the erosion intensity of main channel, $10^{8} \mathrm{t} / \mathrm{d}$; $\Delta t$ is the duration of each flood scale, $\mathrm{d} ; \Delta M$ is the cumulative amount of the main channel in the period, $10^{8} \mathrm{t}$. It can be seen from Table 1 that on the one hand, at the scale of 1250 and $1500 \mathrm{~m}^{3} / \mathrm{s}$, the increasing amplitude of the erosion is not obvious. However, after the discharge is greater than $1750 \mathrm{~m} 3 / \mathrm{s}$, the erosion intensity is greatly improved. This is because the sediment transport capacity at the first two stages is generally small, and the hydrodynamic effect is relatively weak. In the latter two stages, the sediment transport capacity is increased and the effect of hydrodynamics is enhanced, so the increase in erosion is more significant.

Table 1 Erosion amount and intensity under two scenarios

\begin{tabular}{ccccc}
\hline \multirow{2}{*}{$\begin{array}{c}\text { Discahrge } \\
\left(\mathrm{m}^{3} / \mathrm{s}\right)\end{array}$} & \multicolumn{2}{c}{ Scenario one } & \multicolumn{2}{c}{ Scenario two } \\
\cline { 2 - 5 } & $\begin{array}{c}\text { Emount } \\
\left(10^{8} \mathrm{t}\right)\end{array}$ & $\begin{array}{c}\text { Erosion } \\
\text { intensity } \\
\left(10^{8} \mathrm{t} / \mathrm{d}\right)\end{array}$ & $\begin{array}{c}\text { Erosion } \\
\text { amount } \\
\left(10^{8} \mathrm{t}\right)\end{array}$ & $\begin{array}{c}\text { Erosion } \\
\text { intensity } \\
\left(10^{8} \mathrm{t} / \mathrm{d}\right)\end{array}$ \\
\hline 1250 & 0.14 & 0.0093 & 0.11 & 0.0073 \\
1500 & 0.19 & 0.0127 & 0.14 & 0.0093 \\
1750 & 0.28 & 0.0187 & 0.23 & 0.0153 \\
2000 & 0.36 & 0.0240 & 0.29 & 0.0193 \\
2500 & 0.43 & 0.0287 & 0.37 & 0.0247 \\
3000 & 0.41 & 0.0273 & 0.34 & 0.0227 \\
\hline
\end{tabular}

On the other hand, while the discharge increases, the extent of overbank increases correspondingly and the hydrodynamic characteristics of the river channel are weakened. Besides, for the alluvial rivers, the riverbed is gradually roughened due to the erosion of the main channel, which in turn inhibits the erosion of the river channel. The superposition of these two effects makes the main channel erosion intensity behave such changing trends.

According to the variation law of erosion intensity $\phi$ at different discharge levels, it is recommended that the regulation discharge of the Daliushu Reservoir be maintained above $2000 \mathrm{~m}^{3} / \mathrm{s}$ and multi-stage discharge should be adopted during flood seasons. For the determination of the man-made flood duration, we suggests that the duration of single-discharge should be controlled for more than 16 days.

\section{CONCLUSION}

In past 60 years, the continuous deposition occurs in the NMYR because of the upstream reservoir regulation, water use along the river and climate change. Meanwhile, the existing backbone reservoirs have certain limitations in coordinating the relationship between channel restoration and water supply as well as power generation, which poses essential demand for the Daliushu Reservoir. This paper employed the 3-D numerical model to evaluate the response to the man-made flood by Daliushu Reservoir. It is found the inlet ISC is 0.0015 and $0.0025 \mathrm{~kg} . \mathrm{s} / \mathrm{m}^{6}$, the riverbed state of the whole river is eroded, accompanied by the channel erosion, which is more favorable for the recovery of the river channel. Further analysis of the cumulation erosion process shows that there is a nonlinear response relationship between the erosion characteristics of the main channel and the incoming water-sediment conditions, and the maximum erosion intensity is generally achieved at the discharge of $2500 \mathrm{~m}^{3} / \mathrm{s}$. It is recommended that the recent regulation discharge of the river be maintained above $2000 \mathrm{~m}^{3} / \mathrm{s}$ and duration of single-discharge be controlled for more than 16 days.

\section{Acknowledgments}

This work is supported by the National Key R\&D Program of China (Item Nos. 2016YFC0402209). The authors also appreciate the insightful comments and suggestions from anonymous reviewers.

\section{References}

1. An, C. H., Luo, Q. S., \& Li, W. X. (2016). Comprehensive study on river channel control measures in ingxia-Inner Mongolia reach of the Yellow River. Zhengzhou: Yellow River Engineering Consulting Limited Company. (in Chinese)

2. Duan G., Chen S., Qian Y. (2013). Feasibility Study of Harnessing River Siltation Shrinkage by Water and Sediment Regulation. Journal of Yellow River, 35(10), 42-44. (in Chinese)

3. Fan X., Shi C., Shao W. (2013). The suspended sediment dynamics in the Inner-Mongolia reaches of the upper Yellow River. Catena, 109: 72-82.

4. Li X., Zhong D., Zhang Y., Wang Y., Wang Y., and Zhang H. (2018) Wide river or narrow river: Future river training strategy for Lower Yellow River under global change. International Journal of Sediment Research, https://doi.org/10.1016/j.ijsrc.2018.04.001.

5. Ling H., Wang X., Wang Y., Zhong D., Zhang H. (2015). Research on the Flow and Sediment Conditions and Critical Incoming Sediment Coefficient in Ningxia Section of Yellow River. 
Journal of Yellow River, 37(2), 19-23. (in Chinese)

6. Liu, C., Sui, J., Wang, Z. (2008). Sediment load reduction in Chinese rivers. International Journal of Sediment Research, 23(1), 44-55.

7. Liu, F., Chen, S., Peng, J., Chen, G. (2012). Temporal variations of water discharge and sediment load of Huanghe River, China. Chinese Geographical Science, 22(5), 507-521.

8. Liu X., Hou S., Chang W. (2009). Cause of main channel shrinkage occurred to the Inner-Mongolia reaches of Yellow River. Journal of Hydraulic Engineering, 40(9), 1048-1054. (in Chinese)

9. Qin Y., Zhang X., Wang F. (2011). Scour and silting evolution and its influencing factors in Inner Mongolian Reach of the Yellow River. Journal of Geographical Sciences, 21(6): 1037-1046.

10. Ran L., Wang S., Fan X. (2010). Channel change at Toudaoguai Station and its responses to the operation of upstream reservoirs in the upper Yellow River. Journal of Geographical Sciences, 20(2): 231-247.

11. Shi, H.L., Hu, C.H., Wang, Y.G., Hu, J. ( 2014). Analysis on variation trends of runoff and sediment of the Yellow River Basin reasons discussion. Journal of Yellow River, 36(4), 1-5. (in Chinese)

12. Wang Y., Wu B., Zhong D. (2016). Calculation method for sediment load in flood and non-flood seasons in the Inner Mongolia reach of the Yellow River. Journal of Geographical Sciences, 06: 707-721.

13. Zhang Y, Baptista A M. (2008). SELFE: A semiimplicit Eulerian-Lagrangian finite-element model for cross-scale ocean circulation. Ocean Modelling, 21(3-4): 71-96.

14. Zhong D., Wang Y., L X. (2016) Report on the evolution of river channel erosion and deposition in Ningxia-Inner Mongolia reach of the Yellow River. Beijing: Tsinghua University. (in Chinese) 